\title{
Forming and implementing community advisory boards in low- and middle-income countries: a scoping review
}

\author{
Yang Zhao ${ }^{1}$, Thomas Fitzpatrick ${ }^{1,2}$, Bin Wan $^{3}$, Suzanne Day ${ }^{4}$, Allison Mathews ${ }^{4}$ and Joseph D. Tucker ${ }^{1,4,5,6^{*}}$ (D)
}

\begin{abstract}
Background: Community advisory boards (CABs) have expanded beyond high-income countries (HICS) and play an increasing role in low- and middle-income country (LMIC) research. Much research has examined CABs in HICs, but less is known about CABs in LMICs. The purposes of this scoping review are to examine the creation and implementation of CABs in LMICs, including identifying frequently reported challenges, and to discuss implications for research ethics.
\end{abstract}

Methods: We searched five databases (PubMed, Embase, Global Health, Scopus, and Google Scholar) for publications describing or evaluating CABs in LMICs. Two researchers independently reviewed articles for inclusion. Data related to the following aspects of CABs were extracted from included publications: time, country, financial support, research focus, responsibilities, and challenges. Thematic analyses were used to summarize textual data describing challenges.

Results: Our search yielded 2005 citations, 83 of which were deemed eligible for inclusion. Most studies (65) were published between 2010 and 2017. Upper-middle-income countries were more likely to have studies describing CABs, with South Africa (17), China (8), and Thailand (7) having the greatest numbers. The United States National Institutes of Health was the main source of financial support for CABs. Many CABs $(53 / 88,60 \%)$ focused on HIV research. Thirty-four studies reported how CABs influenced the informed consent process for clinical trials or other aspects of research ethics. $C A B$ responsibilities were related to clinical trials, including reviewing study protocols, educating local communities about research activities, and promoting the ethical conduct of research. Challenges faced by CABs included the following: incomplete ethical regulations and guidance; limited knowledge of science among members of communities and CABs; unstable and unbalanced power relationships between researchers and local communities; poor $C A B$ management, including lack of formal participation structures and absence of CAB leadership; competing demands for time that limited participation in $C A B$ activities; and language barriers between research staff and community members. Several challenges reflected shortcomings within the research team.

Conclusions: Our findings examine the formation and implementation of CABs in LMICs and identify several ethical challenges. These findings suggest the need for further ethics training among CAB members and researchers in LMICS.

Keywords: Community advisory boards, Research ethics, Low- and middle-income countries, Scoping review

\footnotetext{
* Correspondence: jdtucker@med.unc.edu

'University of North Carolina at Chapel Hill - Project China, No.2 Lujing Road,

Guangzhou 510095, China

${ }^{4}$ Institute for Global Health and Infectious Diseases, University of North

Carolina at Chapel Hill, Chapel Hill, USA

Full list of author information is available at the end of the article
}

(c) The Author(s). 2019 Open Access This article is distributed under the terms of the Creative Commons Attribution 4.0 International License (http://creativecommons.org/licenses/by/4.0/), which permits unrestricted use, distribution, and reproduction in any medium, provided you give appropriate credit to the original author(s) and the source, provide a link to the Creative Commons license, and indicate if changes were made. The Creative Commons Public Domain Dedication waiver (http://creativecommons.org/publicdomain/zero/1.0/) applies to the data made available in this article, unless otherwise stated. 


\section{Background}

Organizing research studies in low- and middle-income countries (LMICs) present a number of challenges, including difficulties in ensuring community consultation [1-3]. Many funders now require that clinical trials engage with participating communities [4-6]. Community engagement is the process of working collaboratively with relevant stakeholders to address health-related issues that concern them $[7,8]$. Community engagement can empower communities by actively soliciting input from potential research subjects, involving them in decision making, and ensuring their perspectives, attitudes, and values are respected [9]. Moreover, community engagement can build community trust in research, facilitate participant enrollment, and assist in post-trial implementation $[4,6,8,10]$.

Community advisory boards (CABs) are a wellestablished form of community engagement to strengthen research ethics $[8,11,12]$. The United States (US) National Institutes of Health (NIH) officially mandated $\mathrm{CAB}$ inclusion in all HIV clinical trials in 1987 [13]. CABs are typically composed of diverse individuals selected to represent researched communities [14]. Through organizing activities such as community consultations and regular feedback meetings, CABs provide trial participants and potential participants with an opportunity to understand the research process and voice concerns [15]. CABs also advocate for trial participants and promote the ethical conduct of research [14, 15].

Over the past three decades, CABs have become a standard mechanism for community engagement in HIV clinical trials conducted in high-income countries (HICs) [14, 16-18]. With the growth of the global NIH HIV trials network [19-22], CABs are increasingly formed in LMICs [14, 21]. While much research has examined CABs in HICs [16, 22, 23], these findings may be less relevant in LMIC settings. A growing literature has described CABs in LMICs over the past decade $[16,17,24-26]$. CABs in LMICs operate in environments that are distinct from their HIC counterparts. A range of economic, cultural, social, and historical considerations may constrain CABs in LMICs. The purposes of this scoping review are to provide an overview of the published literature describing the formation, implementation, and frequently reported challenges of CABs in LMICs, and to discuss implications for research ethics.

\section{Methods}

\section{Identifying the research question and relevant studies}

This scoping review followed the methodological framework for conducting a scoping study proposed by Arksey and O'Malley [27]. We first defined the objectives of our scoping review as providing an overview of the published literature describing the formation and implementation of CABs in LMICs, including relevant challenges faced by CABs in LMICs, and discussing implications for research ethics. We then identified relevant studies through an online search. Five databases were searched (PubMed, Embase, Global Health, Scopus, and Google Scholar) for English-language entries examining CABs in LMICs published before 01 December 2017. Search terms included "community advisory"” OR "community advisory board" " OR "community advisory group" OR "community steering committee" " OR "community constituency group*" OR "community collaborative board"" OR "community working group"”.

\section{Selecting studies for inclusion}

Two reviewers (YZ, BW) independently screened titles and abstracts for inclusion. Titles and abstracts focusing on CABs in HICs were excluded. Disagreement about inclusion or exclusion of abstracts was discussed and resolved by consensus between the same two reviewers. Full-text publications were then screened by two reviewers (YZ, BW) who ensured all articles included descriptions of the formation or implementation of a $C A B$, discussions of the challenges involved in operating a $\mathrm{CAB}$, or explorations of the possibility of organizing a $\mathrm{CAB}$ in an LMIC. Studies only referring to a CAB without mentioning related characteristics or in-depth discussion were excluded. Included publications were peer-reviewed articles, book chapters, and detailed summaries of research presented at international conferences. Our scoping review primarily focused on the peer-reviewed full articles, but other publications, including abstracts, were also included to supplement findings and present a more comprehensive overview of CABs in LMICs. The process of study selection is outlined in Fig. 1.

\section{Charting the data}

Data related to the following aspects of CABs were extracted from all publications selected for inclusion: year of publication, country or region in which the $C A B$ was operated, membership, activities, funding sources, research focus, achievements, and challenges. Thematic analyses were conducted to summarize and categorize extracted data.

\section{Results}

Our initial search identified 2005 potentially relevant publications. After screening titles, abstracts, and fulltext manuscripts, 83 publications met selection criteria and were included in our analysis. Sixty-three were peerreviewed articles, fifteen were international research conference abstracts, three were presentations from international research conferences, and two were book 


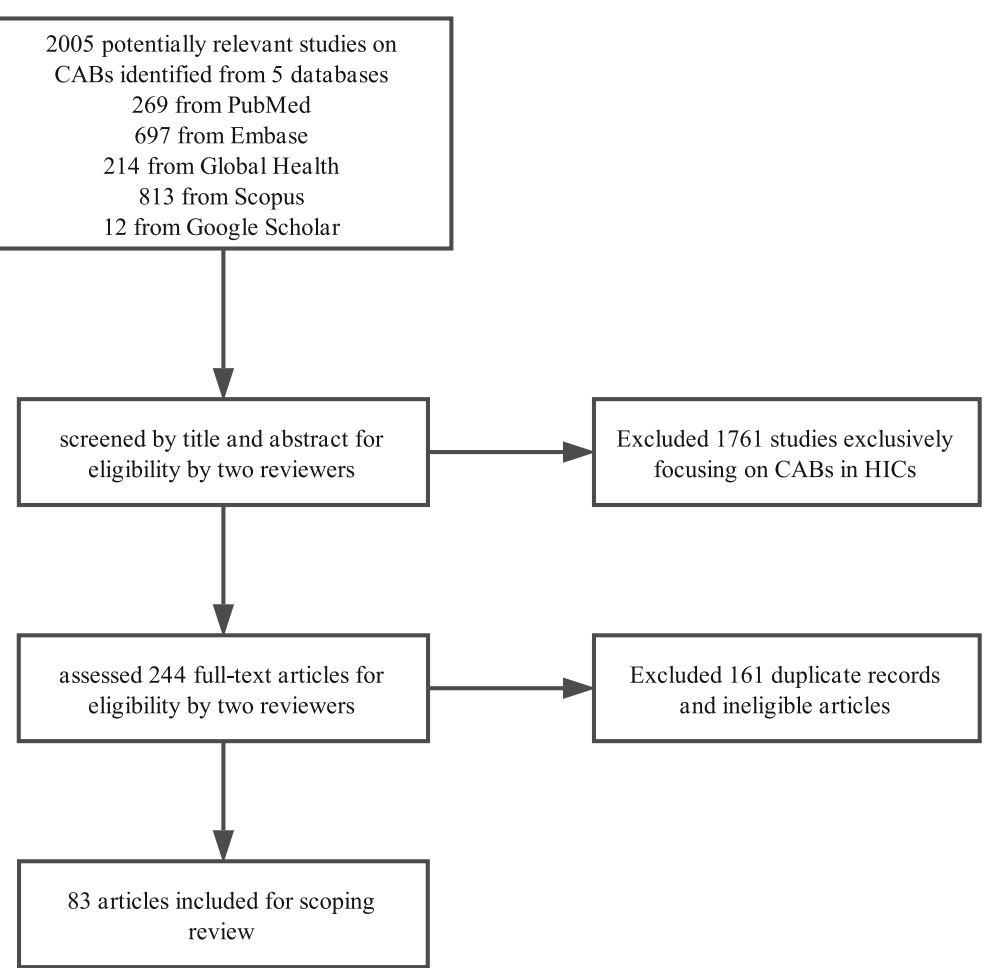

Fig. 1 Selection of included studies

chapters. Two articles published in Chinese with online English abstracts were included as abstracts in our analyses. All abstracts and presentations included a year of publication and country or region, most described a research focus, and only a few presented specific challenges. Twenty publications specifically researched a $\mathrm{CAB}$ in an LMIC using a qualitative approach. The remaining 63 publications described the function of a $\mathrm{CAB}$ in the context of a larger research project.

Year of publication for included publications ranged from 1976 to 2017. Of the 83 included publications, 78\% (65) were published after 2009, and 52\% (43) were published within the last 4 years (Fig. 2). Only one study was published prior to 2000. The 1976 publication

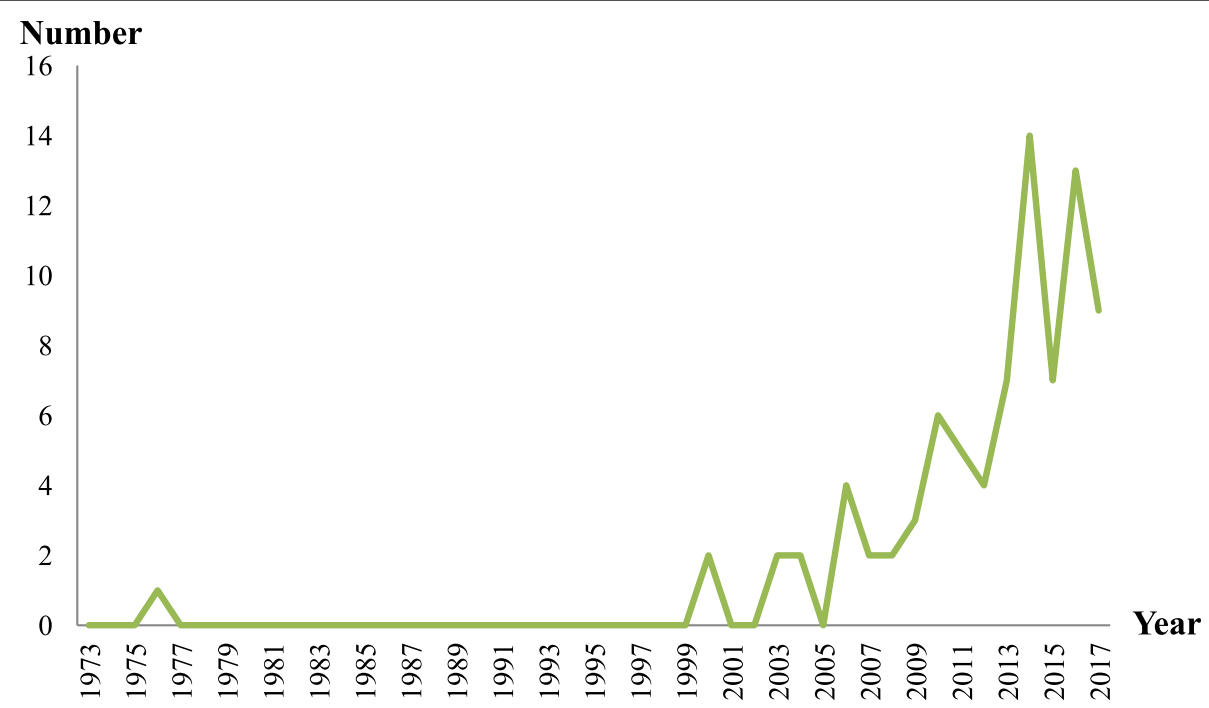

Fig. 2 Number of included publications describing CABs in LMICs by year 
proposed establishing a $\mathrm{CAB}$ to improve the health of rural residents in Thailand [28].

The included publications described 88 different CABs across 26 LMICs and nine geographic regions in Africa, Asia, Oceania, South America, and Europe. The five LMICs with the most CABs were South Africa (17), China (8), Thailand (7), Zimbabwe (6), and India (5). CABs in Africa $(n=49,56 \%)$ and Asia $(n=24,27 \%)$ were disproportionately represented among $88 \mathrm{CABs}$ described in the included publications. Only four CABs were based in South America. Nine studies did not focus on a specific country, but rather a broader geographic region or economic setting (e.g., West Africa, Pacific Islands). Additionally, CABs in LMICs were unevenly distributed across countries in terms of income level. CABs were disproportionately represented in upper-middle-income countries, particularly South Africa, China, and Thailand. In total, thirty-nine CABs in upper-middle-income countries were described, accounting for nearly half of all the CABs identified in this review. In comparison, only 20 and 19 CABs were in lower-middle-income and low-income countries, respectively.

We found 41 included publications provided details on $\mathrm{CAB}$ membership and 24 on the process of $C A B$ membership selection. Members were selected through elections by community members [26], purposive sampling selections by the research team, community members, and sometimes stakeholders [13, 18, 23-25, 29-37], or mixed methods combining several of these strategies $[16,24]$. A common theme in the descriptions of $C A B$ formation was promoting diversity in $\mathrm{CAB}$ membership to ensure adequate representation from key groups. We identified gender, age, religion, class, ethnicity, and religious affiliation as the most commonly used selection factors used to promote diversity in $\mathrm{CAB}$ membership. Additionally, $\mathrm{CABs}$ also proactively included members from stakeholder groups specific to certain LMIC contexts, such as religious leaders $[16,18,19,35,38-40]$, traditional healers $[16,18]$, individuals from different villages, cities, and countries $[17,18]$, media representatives [39], non-governmental organizations workers [31, 41], local politicians [42], patients and family members [19, 43-45], refugees [46], and groups at increased risk of HIV infection (e.g., sex workers, men who have sex with men, and miners) [16, 19, 41, 47].

$C A B$ activities included training sessions, periodic meetings, focus group discussions, site visits, conference calls, and group emails. Ten articles described training sessions for $C A B$ members, including technical medical expertise trainings, $\mathrm{CAB}$ and community leadership skills improvement sessions, protocol specific training, report writing guidance, and protection of research participants, which typically lasted several days and were uniformly conducted before CABs began operating in their advisory capacity $[13,18,26,33]$. Most $C A B$ members had no formal medical or public health training, and consequently organizing teams (e.g. research teams, staff from professional training institutions, and universities) tended to focus training on improving members' medical knowledge as well as addressing research goals and ethics [13, 18, 33, 38, 45, 48, 49]. Once formed, most CABs held periodic meetings, with meeting frequently ranging from weekly to monthly to quarterly to yearly. Meetings typically focused on reporting and discussing progress in preparing, designing or implementing clinical trials (e.g. updates on study findings and current ethical challenges). Thirty-four studies reported how CABs influenced clinical trial informed consent or other aspects of research ethics. CAB activities also included educating communities about research activities and facilitating qualitative research related to ongoing clinical trials.

Most CABs in LMICs were supported through funding from the $\mathrm{NIH}$ or other research institutions based in HICs. Among the $34 \mathrm{CABs}$ whose funding sources were reported, $41 \%$ (14) were part of projects that were entirely funded by the NIH. Seven CABs were part of projects that were funded by European institutions, including the Wellcome Trust (4), National Belgian Lottery Fund (1), and German Federal Ministry of Education and Research (1). Eleven CABs received financial support by being part of projects from both domestic and foreign sources. For example, a CAB in Tanzania was part of a project that was funded by the Ifakara Health Institute with support from both Switzerland and Tanzania, and a CAB in India received funding by being part of a project from the Indian Council of Medical Research and the NIH [37]. Only one $\mathrm{CAB}$ located in South Africa received funding exclusively from domestic sources.

Most CABs (53 publications, 60\%) in our sample advised on HIV research [50-60], vaginal microbicides [61, 62], and antiretroviral medication adherence [37]. Seven CABs advised on research related to other infectious diseases, including tuberculosis $[17,18]$ and malaria [38, 63]. Eight CABs focused on research for non-infectious diseases, including stroke, cancer, malnutrition, and mental illness [30, 35, 39, 64-69]. 19 CABs did not address a specific disease and instead focused on healthcare delivery and public health campaigns generally, including rural and primary healthcare services [46, 70-77]. Finally, one $C A B$ advised on non-medical research, namely, earthquake preparedness [78]. CAB research foci are presented in Fig. 3.

Fourteen of the included publications provided detailed descriptions of $\mathrm{CAB}$ achievements. According to these descriptions, CABs in LMICs improved recruitment strategies, enhanced relationships between researchers and local communities, and addressed ethical 


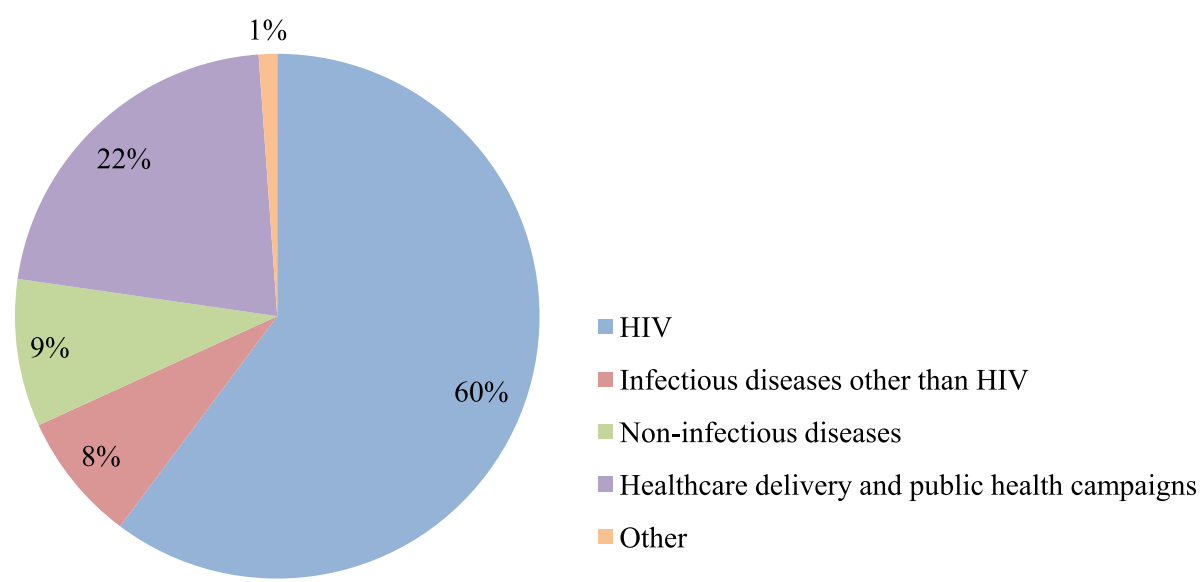

Fig. $3 C A B$ research foci in $L M I C S$

concerns related to participant risk in collaboration with institutional review boards (IRBs). For example, the CAB in a South African schizophrenia genomics study helped individual research participants decide about data sharing [25]. Some researchers may lack specialized knowledge of specific locations and sub-cultures within a diverse region [64]. As part of the community, CABs were often presented as a 'bridge,' 'belt,' 'link,' or 'intermediary' that helped to solidify partnerships between researchers and community members $[13,16]$. CABs were described as an efficient tool to ensure that $C A B$ and community members understood the goals of clinical trials by providing detailed explanations and facilitating discussions [35, 79]. Informed consent forms were identified as complex, legalistic, and difficult to understand for vulnerable populations in LMIC settings. CABs addressed concerns with informed consent language [79]. CABs also contributed to study recruitment by refining recruitment strategies and protecting research participants and the wider community from research-related risk [25].

Challenges faced by CABs in LMICs were specifically addressed by $62 \%$ (39) of the 63 included articles and $35 \%$ (7) of the included abstracts and presentations. After performing thematic analysis of reported challenges, we categorized challenges facing CABs in LMICs into six main types: (1) incomplete ethical regulations and guidance, (2) limited knowledge of science, (3) competing demands, (4) unbalanced power relations, (5) poor $\mathrm{CAB}$ management, and (6) language barriers.

\section{Incomplete ethical regulations and guidance}

Thirteen publications highlighted the absence of guidance on ethical regulations as having negatively impacted the work of CABs in LMICs [5, 16, 24, 31, 46, 79-86]. Incomplete ethical regulations may engender harm or result in exploitation of participating communities, particularly in
LMICs where populations are often disadvantaged, marginalized, or under-resourced. Because of the possibilities of exploitation and unfair benefits in conducting research mentioned by the members of CABs in HIV vaccine trials in South Africa, CAB members and researchers in certain situations felt unprepared to address the tension between generating new knowledge and protecting participants from harm [24]. Essential components of the ethical conduct of clinical research were sometimes unclear to $C A B$ members. For example, $C A B$ members felt uncertain how to ethically enroll minors in sexual and reproductive health research studies, particularly those in early child marriages whose parents did not have parental custody and control [82]. Consequently, CABs may have been unable to adequately perform their function of protecting local participants in research [16, 82, 83]. Given larger power imbalances between CABs in LMICs and researchers from HICs, CAB members at these sites pointed out the need for research projects to leave behind a lasting benefit for their communities [16].

\section{Limited knowledge of science}

Twenty-three publications highlighted knowledge gaps between researchers and members of communities and CABs $[5,13,16,17,25,26,31-37,40,41,44,79-81,84,85$, $87,88]$. It was noted that average members of the population in LMICs, including $C A B$ members, were more likely to have lower levels of education compared to HICs [5,35]. Consequently, authors expressed concerns about $\mathrm{CAB}$ members not fully comprehending the nature of the study and concepts being researched [13, 16, 17, 32, 40, 87, 88]. Since members of communities and CABs had different levels of education and social backgrounds compared to researchers, they may not have fully understood or appreciated researchers' viewpoints, and researchers may have lacked the cross-cultural knowledge and skills necessary to make this knowledge accessible to local communities 
$[13,17,25,31,87]$. For instance, CAB members at one institution were at times unable to explain detailed research procedures to inform communities. This was not only due to the limited science knowledge of participating communities, but also related to the lack of cross-cultural understanding and skills on the part of researchers [33]. Inadequate consideration of community perspectives on the part of research teams has contributed to miscommunication in many research studies [31].

\section{Unstable and unbalanced power relations}

Unstable and unbalanced power relations among $C A B$ members and between $C A B$ members and researchers were identified in 18 publications [5, 18, 24, 26, 31, 33, $35,36,38,45,57,63,64,81,87,89-91]$. CAB members were sometimes less likely to challenge the opinions of doctors and researchers because of internalized perceptions that it was inappropriate to question those in positions of authority [5]. Political tensions were specifically identified as impacting $C A B$ operations in China [89], South Africa [24], and along the Thai-Myanmar border $[5,38,63]$. The diversity of religious, political, language, and ethnic groups along the Thai-Myanmar border raised questions as to what constituted a community and who may serve as a community representative. Moreover, due to incomplete $\mathrm{CAB}$ membership selection criteria [87], marginalized groups tended to be overlooked during $\mathrm{CAB}$ formation. For instance, the electoral model used to establish CABs at the HIV vaccine trial sites in South Africa was not purely democratic, as they elected one person to represent all the 50 families during an ad hoc meeting [24]. The selection of CAB representatives was not always democratic. One CAB was composed of individuals selected only by chiefs or health care workers [33]. The membership and participation of some women in a South African CAB were limited due to the impact gender-based violence on the selection process $[29,87]$. Few CABs used an electoral model to select members, and many CABs lacked a formal structure for participation [5,33]. These complex and politically sensitive issues were difficult for $C A B$ organizers to resolve [45]. Efforts to implement $\mathrm{CAB}$ activities among target populations were impeded by social hierarchies due to age, gender, experience, and social status in several contexts [5, 31, 57, 91].

\section{Poor CAB management}

Poor $\mathrm{CAB}$ management was discussed as a challenge in fourteen publications $[5,13,17,18,24,26,29,33,34,38$, $81,85,87,92]$. Some researchers were inadequate in providing targeted and appropriate trainings for $C A B$ members $[17,26,34,81,85]$. Due to poor training, some $C A B$ members may not have developed the skills necessary to provide feedback to researchers and liaise with their peers. For example, some research teams acknowledged that in the beginning of their clinical trial they did not engage with the CABs in Malawi, invite them to meetings, or provide them with the necessary background information on the clinical trial [26]. Consequently, the broader community may not have appreciated the value of $C A B$ engagement [13, 17]. Additionally, several CABs lacked leadership structures, which negatively impacted $C A B$ functionality $[13,33]$. Some CABs were also required to work on several research projects simultaneously, potentially affecting members' ability to sufficiently focus on particular research issues $[18,38]$.

\section{Competing demands}

Thirteen publications reported that $\mathrm{CAB}$ attendance was negatively affected by other competing demands $[5,13$, 16, 17, 26, 32, 33, 35, 37, 41, 64, 81, 85]. Professional and social obligations, including employment, business dealings, and social activities [33], prevented members from consistently participating in $\mathrm{CAB}$ meetings and activities. The demands of full-time employment were specifically identified as being a challenge for CABs in four publications [13, 33, 35, 81]. For example, competing work demands limited the number of participants who voted at one $C A B$ [33]. Limited economic resources and insufficient compensation for $C A B$ participation were identified as a cause of $C A B$ member dissatisfaction in several included publications [17, 33, 85]. For example, community leaders in five studies reported difficulty convincing $\mathrm{CAB}$ members to regularly attend $\mathrm{CAB}$ meetings because of insufficient participation incentives $[16,26,37,41,64]$. However, there was also disagreement as to whether participation in CABs should be driven by financial incentives or a sense of volunteerism that was primarily motivated by altruism [13].

\section{Language barriers}

Language barriers were identified as a challenge in eleven publications [5, 35, 36, 38-40, 85, 91, 93-95]. $\mathrm{CAB}$ members sometimes had low literacy levels and could not sign their name or read documents related to research projects $[5,40]$. Multiple languages and dialects were spoken across or within several of the communities in which CABs were based, creating challenges for communication between researchers and $\mathrm{CAB}$ members [35, 38, 39, 91]. English proficiency was uncommon among CAB members in LMICs [35, 36, 85], and in certain situations the number of translators was insufficient [93], which further hindered communication. Researchers also tended to have limited abilities in speaking local languages or dialects, although few articles discussed this limitation in detail. One $C A B$ along the Thai-Myanmar had twelve of the fourteen founding 
members unable to speak proficient English, and researchers could not understand the diverse local languages and dialects, which made communication between researchers and the $\mathrm{CAB}$ challenging [5],

\section{Discussion}

This scoping review examines the formation, operation, and challenges of CABs in LMICs and discusses implications for research ethics. Many CABs have focused on HIV clinical trials in upper-middle income countries. Some studies described how CABs influenced the informed consent process and helped address ethical concerns in clinical trials. Several challenges in implementing CABs in LMICs were identified, particularly challenges related to ethics guidance and regulations.

Most of the CABs in LMICs described in the included publications focused on HIV. This may be due to the growth of the global NIH HIV trials network in LMICs and HIV trials being more likely to publish on CABrelated experiences. In contrast, CABs in HICs have advised on more diverse clinical trials [96-104], ranging from cardiovascular disease to mental health. This difference in breadth of research foci may be due to the fact that the majority of NIH-funded trials in LMICs have investigated HIV. As the number of chronic disease trials increase in LMICs $[105,106]$, CABs may be able to expand as well. Some CABs originally focused on HIV have already transitioned to include chronic diseases [25, 30, 35, 39, 64, 107].

We found that most CABs described in the existing literature were based in upper-middle-income countries. Only 19 of the CABs included in this review were based in low-income countries. This finding is consistent with prior reviews which found that few studies have investigated community engagement in low-income countries $[8,108,109]$. Because clinical trials are often conducted in low-income countries [110-112], future investigations of CABs should focus on the accomplishments and challenges specific to this context.

Limited knowledge of science among members of communities and CABs was a common challenge noted among CABs in LMICs. Most included publications attributed this challenge to the different levels of education and social backgrounds and experience between researchers and members of communities and CABs. Eighteen publications mentioned that community members had better knowledge of local cultural and social contexts compared to researchers $[5,12,13,24,25,28$, $29,31,36,39,43,48,50,57,62-64,84]$. Eleven publications also discussed community perceptions of the limitations of researcher-community connections in LMICs related to knowledge gaps and failure to provide enough training in science $[13,16,17,24,31,33,35,40,85,88$, 95]. It is worth noting that researchers may also have lacked the skills necessary to communicate scientific knowledge in understandable and meaningful ways to participating communities. $\mathrm{CAB}$ training helped to build capacity and knowledge among members and researchers $[113,114]$. This also suggests the need for further $C A B$ member and researcher training [16]. Limited knowledge of science was closely connected with language barriers, another challenges that exposed the limitations on the parts of both $C A B$ members and researchers.

Our data suggest that $C A B$ members sometimes had insufficient ethics guidance. Some researchers were inadequate in providing targeted and appropriate trainings for CAB members $[17,26,34,81,85]$, and only seven publications mentioned $C A B$ members had received training on ethics $[13,18,33,38,45,48,49]$. Thirteen publications highlighted the absence of guidance on ethical regulations of CABs in LMICs and suggested the importance of ethics training $[5,16,24,31,46,79-86]$. Several ethics guidance documents related to HIV research have been developed [115-117]. However, our review suggests these documents have not been widely incorporated into standard $C A B$ operations in LMICs. Future research in LMICs should consider incorporating pre-existing ethics documents, including ethics guidelines, statements of shared principles, and other contextualized ethics documents, into $C A B$ member training so that CABs are better prepared to address ethical concerns.

Our study has several limitations. First, we identified challenges facing CABs in LMICs based on published literature, largely reflecting the perspective of research teams. There are fewer perspectives from communities themselves in the literature and our review is less able to capture these important perspectives. Second, our search was limited to English language publications. English is not the primary language in many LMICs, and we may have missed studies in local languages. In addition, the failure to search through Spanish and French language publications may have biased our sample. There may additional relevant publications written in local languages highlighting the challenges we did not identify in this review. Third, we included all types of publications, including peer-reviewed articles, international research conference abstracts and presentations. While this review primarily based its analysis on data extracted from peer-reviewed articles, we also included abstracts and presentations to reinforce and complement our findings. The different levels of information richness across publications may mean that some $C A B$ characteristics were only reported by a subset of studies. Finally, this was not a systematic review. Inferences about CABs in other settings should be made with caution.

Our findings have implications for LMIC research ethics. First, CABs allow an opportunity to consider 
research ethics prior to formal IRB review [118]. CABs engage diverse community members and may facilitate deliberations about ethical concerns from the community which can improve the quality of research and pre-empt issues that may later be identified during formal IRB review [119]. Research ethics goes beyond IRB approval alone and CABs can help to broaden discussions about research ethics in communities [120]. Second, only some studies reported the extent to which CABs advising a clinical trial influenced informed consent and research ethics. This suggests the need for further research about how $\mathrm{CAB}$ activities impact, or fail to impact, the conduct of clinical trials. Third, our data suggest that capacity building is needed among both CABs in LMICs and researchers. Training for $C A B$ members to clarify ethics regulations and theory may be useful. Researchers may also require additional training to better appreciate the importance of community engagement, improve communication skills, and potentially learn local languages or dialects used in participating communities. Finally, challenges arising from the local contexts were frequently reported in our included articles. Issues specific to LMIC contexts, such as the high prevalence of child marriage, should be fully understood and taken into consideration when $\mathrm{CABs}$ and researchers work together to address ethical challenges.

\section{Conclusions}

CABs may be a useful tool for increasing community engagement and the ethical conduct of research in LMICs. This scoping review describes the implementation and operations of CABs in LMICs, including challenges faced by these organizations, and discusses the implications for research ethics. We found several shortcomings and opportunities for increasing $\mathrm{CAB}$ understanding of research ethics. These findings can help inform training and related activities to enhance CABs in LMICs.

\section{Abbreviations}

AIDS: Acquired Immune Deficiency Syndrome; CABs: Community Advisory Boards; HICs: High-income Countries; HIV: Human Immunodeficiency Virus; LMICs: Low- and Middle-income Countries; NIH: National Institutes of Health; US: United States

\section{Acknowledgements}

The authors would like to thank Dr. Linghua Li, Ms. Amy Lee, and Ms. Bingyao Huang for their assistance. We also thank searcHIV team members who provided feedback in a multi-site conference at UNC in February, 2018. Part of this manuscript was presented as The Lancet-CAMS Health Summit 2018 and published as an abstract in a supplement to The Lancet [120].

\section{Authors' contributions}

YZ and JT designed the study protocol, and searches were run by $Y Z, B W$, and an intern of UNC - Project China. Citations, abstracts and full texts were read and selected by $Y Z, B W$ and the intern. Data extraction and analysis were mainly conducted by $Y Z$ with assistance from BW, TF and JT. The manuscript was prepared by $Y Z$ with substantial contributions and edits provided by TF, JT, SD, AM, and BW. All authors read and approved the final manuscript.

\section{Funding}

This work was supported by the National Institute of Health NIAID under Grant \#1R01A108366 and NIAID K24AI143471. The funder has no role in study design, data collection and analysis, preparation of the manuscript, or decision to publish.

\section{Availability of data and materials}

The original dataset is owned by the first author. Researchers interested in using these data can contact $Y Z$ with specific research questions and a proposal.

Ethics approval and consent to participate

Not applicable.

\section{Consent for publication}

Not applicable.

\section{Competing interests}

The authors declare that they have no competing interest.

\section{Author details}

${ }^{1}$ University of North Carolina at Chapel Hill - Project China, No.2 Lujing Road, Guangzhou 510095, China. ${ }^{2}$ University of Washington School of Medicine, Seattle, USA. ${ }^{3}$ Department of Maternal and Child Health, School of Public Health, Sun Yat-sen University, Guangzhou, China. ${ }^{4}$ Institute for Global Health and Infectious Diseases, University of North Carolina at Chapel Hill, Chapel Hill, USA. ${ }^{5}$ School of Medicine, University of North Carolina at Chapel Hill, Chapel Hill, USA. ${ }^{6}$ Faculty of Infectious Diseases, London School of Hygiene and Tropical Medicine, London, UK.

Received: 1 June 2018 Accepted: 16 September 2019 Published online: 17 October 2019

\section{References}

1. Ford JG, Howerton MW, Lai GY, Gary TL, Bolen S, Gibbons MC, et al. Barriers to recruiting underrepresented populations to cancer clinical trials: a systematic review. Cancer. 2008;112(2):228-42. https://doi.org/10.1002/cncr.23157.

2. Killien M, Bigby JA, Champion V, Fernandez-Repollet E, Jackson RD, Kagawa-Singer $M$, et al. Involving minority and underrepresented women in clinical trials: the National Centers of excellence in Women's health. J Women's Health Gender-Based Med. 2000;9(10):1061-70. https://doi.org/ 10.1089/152460900445974.

3. Harris Y, Gorelick PB, Samuels P, Bempong I. Why African Americans may not be participating in clinical trials. J Natl Med Assoc. 1996;88(10):630-4.

4. Ahmed SM, Palermo A-GS. Community engagement in research: frameworks for education and peer review. Am J Public Health. 2010;100(8): 1380-7. https://doi.org/10.2105/AJPH.2009.178137.

5. Cheah PY, Lwin KM, Phaiphun L, Maelankiri L, Parker M, Day NP, et al. Community engagement on the Thai-Burmese border: rationale, experience and lessons learnt. Int Health. 2010;2(2):123. https://doi.org/10.1016/j.inhe. 2010.02.001

6. Holzer JK, Ellis L, Merritt MW. Why we need community engagement in medical research. J Invest Med. 2014;62(6):851-5. https://doi.org/10.1097/ JIM.0000000000000097.

7. World Health Organization. WHO community engagement framework for quality, people-centred and resilient health services. In: Service delivery and safety. World Health Organization. 2018. http://www.who. int/servicedeliverysafety/areas/qhc/community-engagement/en/. Accessed 30 May 2018

8. Tindana PO, Singh JA, Tracy CS, Upshur REG, Daar AS, Singer PA, et al. Grand challenges in global health: community engagement in research in developing countries. PLoS Med. 2007;4(9):e273. https://doi.org/10.1371/ journal.pmed.0040273.

9. Zhang A, Pan X, Wu F, Zhao Y, Hu F, Li L, et al. 'What would an HIV cure mean to you?': qualitative analysis from a crowdsourcing contest in Guangzhou, China. AIDS Res Hum Retrovir. 2018;34(1):80-7. https://doi.org/ 10.1089/AID.2017.0188

10. Slevin KW, Ukpong M, Heise L. Community engagement in HIV prevention trials: evolution of the field and opportunities for growth. In: AIDS2031 Background Paper. Global Campaign for Microbicides. 2018. https://www.path. org/publications/files/aids2031_comm_engage.pdf. Accessed 30 May 2018. 
11. Quinn SC. Protecting human subjects: the role of community advisory boards. Am J Public Health. 2004;94(6):918-22.

12. Cheah PY, Lwin KM, Nosten F, Parker M. Key success indicators of a community engagement strategy: the case of a tropical medicine research unit on the Thai-Myanmar border. Am J Trop Med Hyg. 2015;93(Suppl 4):408-9.

13. Mwinga A, Moodley K. Engaging with community advisory boards (CABs) in Lusaka Zambia: perspectives from the research team and CAB members. BMC Medical Ethics. 2015;16(1):1-11. https:/doi.org/10.1186/s12910-015-0031-y.

14. International AIDS Vaccine Initiative. Guidance tool for community advisory boards. In: Training manual. International AIDS Vaccine Initiative. 2012. https://www.iavi.org/media-center/publications/category/20-training-andtoolkits?download=51:guidance-tool-for-community-advisory-boards. Accessed 30 May 2018

15. AIDS Clinical Trials Group. 2017 Core CAB handbook. In: GCAB. AIDS Clinical Trials Group. 2017. https://actgnetwork.org/sites/default/files/files/2018\%2 OCore\%20CAB\%20Handbook.doc. Accessed 30 May 2018.

16. Morin SF, Maiorana A, Koester KA, Sheon NM, Richards TA. Community consultation in HIV prevention research: a study of community advisory boards at 6 research sites. J Acquir Immune Defic Syndr. 2003;33(4):513-20.

17. Shubis K, Juma O, Sharifu R, Burgess B, Abdulla S. Challenges of establishing a community advisory board (CAB) in a low-income, low-resource setting: experiences from Bagamoyo. Tanzania Health Research Policy and Systems. 2009;7:16. https://doi.org/10.1186/1478-4505-7-16.

18. Ntshanga SP, Ngcobo PS, Mabaso MLH. Establishment of a community advisory board (CAB) for tuberculosis control and research in the Inanda, Ntuzuma and Kwamashu (INK) area of KwaZulu-Natal, South Africa. Health Policy. 2010;95(2):211-5. https://doi.org/10.1016/j.healthpol.2009.12.004.

19. Seidel S, Schwalbe, N. Community engagement in clinical trials. In: TB Alliance. Global Alliance for TB Drug Development. 2006. http://www. tballiance.org/downloads/Access/Community-Engagement-in-Clinical-Trials. pdf. Accessed 30 May 2018.

20. Cox LE, Rouff JR, Svendsen KH, Markowitz M, Abrams DI. Community advisory boards: their role in AIDS clinical trials. Health Social Work. 1998;23(4):290-7.

21. Kagan JM, Rosas SR, Siskind RL, Campbell RD, Gondwe D, Munroe D, et al. Community-researcher partnerships at NIAID HIV/AIDS clinical trials sites: insights for evaluation and enhancement. Prog Community Health Partnersh. 2012;6(3):311-20. https://doi.org/10.1353/cpr.2012.0034.

22. NIMH MHSPTFAACG, Mott L, Crawford E. The Role of Community Advisory Boards in Project Eban. J Acquir Immune Defic Syndr. 2008; 49(Suppl 1):S68-74. https://doi.org/10.1097/QAl.0b013e31818447f5.

23. Newman SD, Andrews JO, Magwood GS, Jenkins C, Cox MJ, Williamson DC. Community advisory boards in community-based participatory research: a synthesis of best processes. Prev Chronic Dis. 2011;8(3):A70.

24. Reddy P, Buchanan D, Sifunda S, James S, Naidoo N. The role of community advisory boards in health research: divergent views in the South African experience. SAHARA-J. 2010;7(3):2-8. https://doi.org/10. 1080/17290376.2010.9724963.

25. Campbell MM, Susser E, Vries JD, Baldinger A, Sibeko G, Mndini MM, et al. Exploring researchers' experiences of working with a researcher-driven, population-specific community advisory board in a south African schizophrenia genomics study. BMC Medical Ethics. 2015;16(1):45-53. https://doi.org/10.1186/s12910-015-0037-5.

26. Manda-Taylor L. Establishing community advisory boards for clinical trial research in Malawi: engendering ethical conduct in research. Malawi Med J. 2013;25(4):96-100.

27. Arksey H, O'Malley L. Scoping studies: towards a methodological framework Int J Soc Res Methodol. 2005;8(1):19-32. https://doi.org/10.1080/ 1364557032000119616

28. Vachrotai S. The Lampang project, an alternative approach to rural health care in Thailand. Assignment Children. 1976;33:88-96.

29. Hartmann M, Montgomery E, Stadler J, Laborde N, Magazi B, Mathebula F, et al. Negotiating the use of female-initiated HIV prevention methods in a context of gender-based violence: the narrative of rape. Cult Health Sex. 2015;18(6):1-14. https://doi.org/10.1080/13691058.2015.1101786.

30. Hubbell FA, Luce PH, Afeaki WP, Cruz LAC, McMullin JM, Mummert A, et al. Legacy of the Pacific islander cancer control network. Cancer. 2006;107(8): 2091-8. https://doi.org/10.1002/cncr.22154.

31. Lo B, Bayer R. Establishing ethical trials for treatment and prevention of AIDS in developing countries. BMJ. 2003;327(7410):337. https://doi.org/10. 1136/bmj.327.7410.337
32. Musesengwa R, Chimbari MJ, Mukaratirwa S. Initiating community engagement in an ecohealth research project in southern Africa. Infect Dis Pov. 2017;6(1):22-32. https://doi.org/10.1186/s40249-016-0231-9.

33. Nyirenda D, Sariola S, Gooding K, Phiri M, Sambakunsi R, Moyo E, et al. 'We are the eyes and ears of researchers and community': understanding the role of community advisory groups in representing researchers and communities in Malawi. Dev World Bioeth. 2017:1-9. https://doi.org/10. 1111/dewb.12163.

34. Dickson-Gomez J, Corbett AM, Bodnar G, Zuniga MO, Guevara CE, Rodriguez $\mathrm{K}$, et al. Context and group dynamics in a CBPR-developed HIV prevention intervention. Health Promot Int. 2016;31(1):93-105. https://doi. org/10.1093/heapro/dau058.

35. Singh A, Jenkins C, Calystagoe B, Arulogun OS, Sarfo S, Ovbiagele B, et al. Stroke investigative research and education network: public outreach and engagement. Health Education and Behavior. 2017;7(2):518-35. https://doi. org/10.4172/2161-0711.1000518.

36. Stadler J, Dugmore C, Venables E, Macphail C, Delanymoretlwe S. Cognitive mapping: using local knowledge for planning health research. BMC Med Res Methodol. 2013;13(1):96-108. https://doi.org/10.1186/1471-2288-13-96.

37. Swendeman D, Jana S, Ray P, Mindry D, Das M, Bhakta B. Development and pilot testing of daily interactive voice response (IVR) calls to support antiretroviral adherence in India: a mixed-methods pilot study. AIDS Behav. 2015;19(2):142-55. https://doi.org/10.1007/s10461-014-0983-9.

38. Lwin KM, Cheah PY, Cheah PK, White NJ, Day NPJ, Nosten F, et al. Motivations and perceptions of community advisory boards in the ethics of medical research: the case of the Thai-Myanmar border. BMC Medical Ethics. 2014;15(1):1-10. https://doi.org/10.1186/1472-6939-15-12.

39. Jenkins C, Arulogun OS, Singh A, Mande AT, Ajayi E, Benedict CT, et al. Stroke investigative research and education network: community engagement and outreach within phenomics core. Health Educ Behav. 2016;43(Suppl 1):82S-92S. https://doi.org/10.1177/1090198116634082.

40. Ssali A, Poland F, Seeley J. Exploring informed consent in HIV clinical trials: a case study in Uganda. Heliyon. 2016;2(11):e00196. https://doi.org/10.1016/j. heliyon.2016.e00196.

41. Keygnaert I, Dialmy A, Manço A, Keygnaert J, Vettenburg N, Roelens K, et al. Sexual violence and sub-Saharan migrants in Morocco: a community-based participatory assessment using respondent driven sampling. Glob Health. 2014;10(1):1-16. https://doi.org/10.1186/1744-8603-10-32.

42. Urada LA, Simmons J. Social and structural constraints on disclosure and informed consent for HIV survey research involving female sex workers and their bar managers in the Philippines. J Empir Res Hum Res Ethics. 2014;9(1): 29-40. https://doi.org/10.1525/jer.2014.9.1.29.

43. Williams AB, Wang H, Burgess J, Li X, Danvers K. Cultural adaptation of an evidence-based nursing intervention to improve medication adherence among people living with HIV/AIDS (PLWHA) in China. Int J Nurs Stud. 2013; 50(4):487-94. https://doi.org/10.1016/j.jinurstu.2012.08.018.

44. Kombo AO, Thomas TK, Otieno S, DeCock KM, Vulule J, Slutsker L, et al. Establishment of an urban community advisory board for a clinical trial in Kisumu, Kenya. In: Abstract Archive International AIDS Conference 2004. 2004. http://www.abstract-archive.org/Abstract/Share/42929. Accessed 30 May 2018.

45. Lwin KM, Peto TJ, White NJ, Day NPJ, Nosten F, Parker M, et al. The practicality and sustainability of a community advisory board at a large medical research unit on the Thai-Myanmar border. Health. 2013;5(2): 229-36. https://doi.org/10.4236/health.2013.52031.

46. Robinson C: Enhancing community protection in research on displacement and migration: expanding the roles of community advisory boards. In: Ethics of research with refugees and migrant populations. Global Forum on Bioethics in Research. 2017. http://gfbr.global/wp-content/uploads/2017/12/ CS9.-Court-Robinson.pptx. Accessed 30 May 2018.

47. Gao HCWN, Shi XM, Yang ZM, Qian HZ, Zhao RY, Min XD, Ni WL. Study on sexual behavior and HIV/STIs among miners in Yunnan province. Chin J Epidemiol. 2006;27:5-8.

48. Dykens A, Hedrick C, Ndiaye Y, Linn A. Peace corps partnered health services implementation research in global health: opportunity for impact. Glob Adv Health Med. 2014;3(5):8-15. https://doi.org/10.7453/gahmj.2014.031.

49. Moseki. ME. Striving for a comprehensible informed consent. Trop Med Int Health. 2012;17(Supple 1):75-6. https://doi.org/10.1111/j.1365-3156. 2011.02994 4.x.

50. Essack Z. Ensuring access to HIV prevention services in south African HIV vaccine trials: correspondence between guidelines and practices. Pub Health Ethics. 2014;7(2):195-206. https://doi.org/10.1093/phe/phu010. 
51. Galárraga O, Wamai RG, Sosa-Rubí SG, Mugo MG, Contreras-Loya D, Bautista-Arredondo $\mathrm{S}$, et al. HIV prevention costs and their predictors: evidence from the ORPHEA project in Kenya. Health Policy Plan. 2017;32(10): 1407-16. https://doi.org/10.1093/heapol/czx121.

52. Gunda R, Ruzario S, Chekera R, Phiri M, Gutsire R. Dealing with research participants' complaints in HIV/AIDS prevention studies: experiences from Zimbabwe. Retrovirology. 2012;9(Supple 2):227. https://doi.org/10.1186/ 1742-4690-9-S2-P227.

53. Kumar MS, Mudaliar S, Thyagarajan SP, Kumar S, Selvanayagam A, Daniels D. Rapid assessment and response to injecting drug use in Madras, South India. Int J Drug Policy. 2000;11(1):83-98. https://doi.org/10.1016/S09553959(99)00057-2.

54. Moodley K, Staunton C, de Roubaix M, Cotton M. HIV cure research in South Africa: a preliminary exploration of stakeholder perspectives. AIDS Care. 2016;28(4):524-7. https://doi.org/10.1080/09540121.2015.1112351.

55. Mesquita F, Bueno R, Araujo PJ, Piconez D, Giselda TL, Haddad IMT. Rapidly responding to injecting drug use and HIV in Brazil: a field-report from São Vicente, São Paulo state. Int J Drug Policy. 2000;11(1-2):133-44. https://doi. org/10.1016/S0955-3959(99)00061-4.

56. Moorhouse R, Slack C, Quayle M, Essack Z, Lindegger G. Stakeholder views of ethical guidance regarding prevention and care in HIV vaccine trials. BMC Medical Ethics. 2014;15(1):1-11. https://doi.org/10.1186/1472-6939-15-51.

57. Sahay S, Mehendale S. Engaging community to support HIV prevention research. Eastern J Medicine. 2011;16(2):168-77.

58. Rerks-Ngarm S, Premsri N, Namwat C, Pitisutthithum P, Nitayaphan S, Kaewkungwal J, et al. Community engagement: experience from the Thai phase III prime-boost HIV vaccine trial, RV144. AIDS Vaccine. 2010;26(10):A96. https://doi.org/10.1089/aid.2010.9998.

59. Nyblade L, Singh S, Ashburn K, Brady L, Olenja J. 'Once I begin to participate, people will run away from me': understanding stigma as a barrier to HIV vaccine research participation in Kenya. Vaccine. 2011;29(48): 8924-8. https://doi.org/10.1016/j.vaccine.2011.09.067.

60. Mutengu LKH, Millard M, Nanyondo J, Wabwire-Mangen F, Robb M. Community engagement: innovations in HIV prevention research. Clinical Trials. 2010;7(4):455. https://doi.org/10.1177/1740774510374795.

61. Woodsong C, Mutsambi JM, Ntshele S, Modikoe P. Community and research staff collaboration for development of materials to inform microbicide study participants in Africa. J Int AIDS Soc. 2014;17(Suppl 3):19156. https://doi.org/ 10.7448/IAS.17.3.19156.

62. Gafos M, Mzimela MA, Ndlovu HB, Mccormack S, Mcgrath N. How effective is effective enough? Opinions of potential end-users of microbicides from a rural south African community. AIDS Care. 2013;25(5):573-8. https://doi.org/ 10.1080/09540121.2012.722604.

63. Pratt B, Lwin KM, Zion D, Nosten F, Loff B, Cheah PY. Exploitation and community engagement: can community advisory boards successfully assume a role minimising exploitation in international research. Dev World Bioeth. 2015;15(1):18-26. https://doi.org/10.1111/dewb.12031.

64. Acharya B, Maru D, Schwarz R, Citrin D, Tenpa J, Hirachan S, et al. Partnerships in mental healthcare service delivery in low-resource settings: developing an innovative network in rural Nepal. Glob Health. 2017;13(1):2-8. https://doi.org/ 10.1186/s12992-016-0226-0.

65. Betancourt TS, Meyers-Ohki SE, Stevenson A, Ingabire C, Kanyanganzi F, Munyana $\mathrm{M}$, et al. Using mixed-methods research to adapt and evaluate a family strengthening intervention in Rwanda. Afr J Traumatic Stress. 2011;2(1):32-45.

66. Betancourt TS, Meyers-Ohki S, Stulac SN, Barrera E, Mushashi C, Beardslee WR. Nothing can defeat combined hands (abashize hamwe ntakibananira): protective processes and resilience in Rwandan children and families affected by HIV/AIDS. Soc Sci Med (1982). 2011;73(5):693-701. https://doi. org/10.1016/j.socscimed.2011.06.053.

67. Tindana P, Vries JD, Campbell M, Littler K, Seeley J, Marshall P, et al. Community engagement strategies for genomic studies in Africa: a review of the literature. BMC Medical Ethics. 2015;16(1):1-12. https://doi.org/10. 1186/s12910-015-0014-z.

68. Netshandama V, Boissevain JR, Samie A, Musie E, Guerrant R, Dillingham RA, et al. Building community partnerships for research in Limpopo Province, South Africa. Am J Tropic Med Hygiene. 2010;83(Supple 5):279.

69. Winkler AS, Schmidt V, Ngowi B, Sikasunge C, Phiri IK, Mfinanga S, et al. CYSTINET-Africa: An interdisciplinary network on taenia solium cysticercosis and taeniosis research as well as capacity building in sub-Saharan Africa.
Tropic Med Int Health. 2017;22(Supple 1):89. https://doi.org/10.1111/ (ISSN)1365-3156.

70. Afzal O, Lieber M, Du Preez C, Pearlman Shapiro M, Marie BA. Reproductive healthcare needs of sex workers in rural South Africa: a community assessment. Annals of Global Health. 2016;82(3):397.

71. Chang BL, Robbins WA, Wei F, Xun L, Wu G, Li N, et al. Boron workers in China: exploring work and lifestyle factors related to boron exposure. AAOHN J. 2006;54(10):435-43. https://doi.org/10.1177/216507990605401003.

72. Do LA, Boonmongkon P, Paek SC, Guadamuz TE. Hu Hong'(bad thing): parental perceptions of teenagers' sexuality in urban Vietnam. BMC Public Health. 2017;17(1):226-36. https://doi.org/10.1186/s12889-017-4133-y.

73. Forrest Jl, Kaida A, Dietrich J, Miller CL, Hogg RS, Gray G. Perceptions of HIV and fertility among adolescents in Soweto, South Africa: stigma and social barriers continue to hinder progress. AIDS and Behavior. 2009;13(1):55-61. https://doi.org/10.1007/s10461-009-9552-z.

74. Hunter WM, Sadowski LS, Hassan F, Jain D, De Paula CS, Vizcarra B, et al. Training and field methods in the WorldSAFE collaboration to study family violence. Inj Control Saf Promot. 2004;11(2):91-100.

75. Lofthouse A, Dykens A, Peters K. Advancing implementation science through global health education: a mentored peace corps master's international program. Annals of Global Health. 2016:82(3):476-7.

76. Logan J, Msunza Z, Tesha F, Kasimba A, Ng'Ida F, Sombe N, et al. Social responsibility of the global health researcher: a research ethics video training module. Annals of Global Health. 2016;82(3):477.

77. Sorensen JS, Galvin SR, Maitland AR. Implementing targeted interdisciplinary solutions to health barriers through experiential learning projects: the northwestern access to health project in Mali. Annals of Global Health. 2016; 82(3):393-4.

78. Jamshidi E, Majdzadeh R, Saberi M, Ardalan A, Majdzadeh B, Seydali E. Effectiveness of community participation in earthquake preparedness: a community-based participatory intervention study of Tehran. Disaster Med Public Health Prep. 2016;10(2):211-8. https://doi.org/10.1017/dmp.2015.156.

79. Morin SF, Morfit S, Maiorana A, Aramrattana A, Goicochea P, Mutsambi JM, et al. Building community partnerships: case studies of community advisory boards at research sites in Peru, Zimbabwe, and Thailand. Clin Trials. 2008; 5(2):147-56. https://doi.org/10.1177/1740774508090211.

80. Liu CY, Zhai XM. Operation guideline for community advisory Board for Preventive AIDS research in China. In: Media Center. International AIDS Vaccine Initiative. 2010. https://www.iavi.org/media-center/publications/ category/19-community-preparedness?download=52:operation-guidelinefor-community-advisory-board-for-preventive-aids-research-in-china. Accessed 30 May 2018.

81. Liu CY, Wang CS, Bai J. An investigation on the role of community advisory board played in China acquired immunodeficiency syndrome research and prevention. Chin J Vacc Immun. 2009;15(2):163-6.

82. Folayan MO, Haire B, Harrison A, Fatusi O, Brown B. Beyond informed consent: ethical considerations in the design and implementation of sexual and reproductive health research among adolescents. Afr J Reprod Health. 2014;18(3 Spec):118-26.

83. Sifunda S, Reddy P, Naidoo N, James S, Buchanan D. Recruiting and educating participants for enrollment in HIV-vaccine research: ethical implications of the results of an empirical investigation. Public Health Ethics. 2014;44(7):78-85. https://doi.org/10.1093/phe/pht018.

84. Folayan MO, Brown B, Haire B, Yakubu A, Peterson K, Tegli J. Stakeholders' engagement with Ebola therapy research in resource limited settings. BMC Infect Dis. 2015;15:242-6. https://doi.org/10.1186/s12879-015-0950-8.

85. Thaitawat N, Chinaworapong S. Formulating guidelines for community advisory boards. In Annual meeting forum for ethical review committees in the Asian and Western Pacific region. FERCAP. 2008. http://www.fercapsidcer.org/new_web/doc/ConferencePresentation2008/1125-23Thaitawat. pdf. Accessed May 302018.

86. Suwanphatthana N. Challenges for community engagement in HIV research in Thailand. AIDS Res Hum Retrovir. 2014;30(S1):A107-8. https://doi.org/10. 1089/aid.2014.5203.abstract.

87. Balekang GB. Challenges of establishing and running a community advisory board (CABs) in Botswana. In Seventh EDCTP Forum Programme. EDCTP. 2014. http://www.edctp.org/web/app/uploads/2018/03/Seventh-EDCTPForum-abstract-book.pdf. Accessed 30 May 2018.

88. Mduluza T, Midzi N, Duruza D, Ndebele P. Study participants incentives, compensation and reimbursement in resource-constrained settings. BMC Medical Ethics. 2013;14(Supple 1):S4. https://doi.org/10.1186/1472-6939-14-S1-S4. 
89. Kaufman J, Liu C, Menezes A. Developing community advisory board guidelines for AIDS vaccine trials in China. Retrovirology. 2012;9(Suppl 2): 129. https://doi.org/10.1186/1742-4690-9-S2-P129.

90. Pratt B, Zion D, Lwin KM, Cheah PY, Nosten F, Loff B. Linking international clinical research with stateless populations to justice in global health. BMC Medical Ethics. 2014;15:49. https://doi.org/10.1186/1472-6939-15-49.

91. Aellah G, Chantler T, Geissler PW. Of course we speak English: community engagement and disseminating information. In: Global Health Research in an Unequal World: Ethics Case Studies from Africa; 2016.

92. Slack $C$, Thabethe $S$, Lindegger $G$, Matandika L, Newman PA, Kerr P, et al. "...I've gone through this my own self, so I practice what I preach...": strategies to enhance understanding and other valued outcomes in HIV vaccine trials in South Africa. J Empir Res Hum Res Ethics. 2016;11(4):322-33. https://doi.org/10.1177/1556264616675202.

93. Pratt B, Zion D, Lwin KM, Cheah PY, Nosten F, Loff B. Closing the translation gap for justice requirements in international research. J Med Ethics. 2012; 38(9):552. https://doi.org/10.1136/medethics-2011-100301.

94. Aellah G, Chantler T, Geissler PW. Lost in translation: public communication and power relations. In: Global Health Research in an Unequal World: Ethics Case Studies from Africa; 2016.

95. NIMH Collaborative HIV/STD Prevention Trial Group. Ethical issues in the NIMH collaborative HIV/STD prevention trial. AIDS. 2007;21(Supple 2):S69-80. https://doi.org/10.1097/01.aids.0000266459.49138.b3.

96. Mittelmark MB, Luepker RV, Jacobs DR, Bracht NF, Carlaw RW, Crow RS, et al. Community-wide prevention of cardiovascular disease: education strategies of the Minnesota heart health program. Prev Med. 1986;15(1):1-17.

97. Kimball BC, Nowakowski KE, Maschke KJ, Mccormick JB. Genomic data in the electronic medical record: perspectives from a biobank community advisory board. J Empir Res Hum Res Ethics. 2014;9(5):16-24. https://doi.org/ $10.1177 / 1556264614553922$.

98. Sorlie PD, Aviléssanta LM, Wassertheilsmoller S, Kaplan RC, Daviglus ML, Giachello AL, et al. Design and implementation of the Hispanic community health study/study of Latinos. Ann Epidemiol. 2010;20(8):629-41. https://doi. org/10.1016/j.annepidem.2010.03.015.

99. Ellis BH, Macdonald HZ, Lincoln AK, Cabral HJ. Mental health of Somali adolescent refugees: the role of trauma, stress, and perceived discrimination. J Consult Clin Psychol. 2008;76(2):184-93. https://doi.org/10. 1037/0022-006X.76.2.184

100. Brelandnoble AM, Bell CC. Burriss. "mama just won't accept this": adult perspectives on engaging depressed African American teens in clinical research and treatment. J Clin Psychol Med Settings. 2011;18(3):225-34. https://doi.org/10.1007/s10880-011-9235-6.

101. Simon CM, Newbury E, L'Heureux J. Protecting participants, promoting progress: public perspectives on community advisory boards (CABs) in biobanking. J Empir Res Hum Res Ethics. 2011;6(3):19-30. https://doi.org/10. 1525/jer.2011.6.3.19.

102. Brelandnoble AM, Bell CC, Burriss A, Poole HK. The significance of strategic community engagement in recruiting African American youth and families for clinical research. J Child Fam Stud. 2012;21(2):273-80. https://doi.org/10. 1007/s10826-011-9472-1.

103. Breland-Noble AM. Community and treatment engagement for depressed African American youth: the AAKOMA FLOA pilot. J Clin Psychol Med Settings. 2012:19(1):41-8. https://doi.org/10.1007/s10880-011-9281-0.

104. Horowitz CR, Arniella A, James S, Bickell NA. Using community-based participatory research to reduce health disparities in east and Central Harlem. Mt Sinai J Med. 2004;71(71):368-74.

105. Suhrcke M, Nugent RA, Stuckler D. Chronic disease: an economic perspective; 2006.

106. Banatvala N, Donaldson L. Chronic diseases in developing countries. Lancet. 2007;370(9605):2076-8. https://doi.org/10.1016/S0140-6736(07)61877-7.

107. Perzynski AT, Ramsey RK, Colónzimmermann K, Cage J, Welter E, Sajatovic M. Barriers and facilitators to epilepsy self-management for patients with physical and psychological co-morbidity. Chronic Illness. 2017;13(3):188-203. https://doi.org/10.1177/1742395316674540.

108. Zhang TP, Liu C, Han L, Tang W, Mao J, Wong T, et al. Community engagement in sexual health and uptake of HIV testing and syphilis testing among MSM in China: a cross-sectional online survey. J Int AIDS Soc. 2017; 20(1):1-10. https://doi.org/10.7448/IAS.20.01.21372.

109. Shalowitz MU, Isacco A, Barquin N, Clark-Kauffman E, Delger P, Nelson D, et al. Community-based participatory research: a review of the literature with strategies for community engagement. J Dev Behav Pediatr. 2009;30(4): 350-61. https://doi.org/10.1097/DBP.0b013e3181b0ef14.

110. Grover S, Xu M, Jhingran A, Mahantshetty U, Chuang L, Small W, et al. Clinical trials in low and middle-income countries - successes and challenges. Gynecol Oncol Rep. 2017;19:5-9. https://doi.org/10.1016/j.gore. 2016.11.007

111. Dal-Ré R, Ndebele P, Higgs E, Sewankambo N, Wendler D. Protections for clinical trials in low and middle income countries need strengthening not weakening. BMJ. 2014;349:g4254. https://doi.org/10.1136/bmj.g4254.

112. Alemayehu C, Mitchell G, Nikles J. Barriers for conducting clinical trials in developing countries - a systematic review. Int J Equity Health. 2018:17:37. https://doi.org/10.1186/s12939-018-0748-6.

113. Azizuyo B. The importance of involving young women living with HIV in sexual reproductive health research: International Community of Women Living with HIV Eastern Africa (ICWEA) experience. J Int AIDS Soc. 2016; 19(Supple 5):154-5. https://doi.org/10.7448/IAS.19.6.21264.

114. Dietrich J, Smith T, Cotton L, Hornschuh S, Van Der Watt M, Miller CL, et al. Bridging the gap between adults and adolescents and youth adults (AYA)employing a youth-centred approach to investigate HIV risk among AYA in Soweto and Durban, South Africa. BMC Infect Dis. 2016;16(Supple 2). https:// doi.org/10.1186/s12879-016-1466-6.

115. Rennie S, Sugarman J. Developing ethics guidance for HIV prevention research: the HPTN approach. J Med Ethics. 2010;36(12):810-5. https://doi. org/10.1136/jme.2010.035444.

116. Lo B, Grady C. Ethical considerations in HIV cure research: points to consider. Curr Opin HIV AIDS. 2013;8(3):243-9. https://doi.org/10.1097/COH. Ob013e32835ea1c5.

117. Guenter D, Esparza J, Macklin R. Ethical considerations in international HIV vaccine trials: summary of a consultative process conducted by the joint United Nations Programme on HIV/AIDS (UNAIDS). J Med Ethics. 2000;26(1): 37-43. https://doi.org/10.1136/jme.26.1.37.

118. National Institute of Health. Institutional review board (IRB) of the All of Us Research Program. In: All of Us Research Progam. National Institute of Health. 2019. https://allofus.nih.gov/about/who-we-are/institutional-reviewboard-irb-of-all-of-us-research-program. Accessed 13 May 2019.

119. Stephanie SC. What can IRBs learn from CABs: a qualitative analysis of the experiences of recruitment and training of nonscientist members on research review boards. J Empir Res Hum Res Ethics. 2018;13(1):88-94. https://doi.org/10.1177/1556264617742237.

120. Zhao Y, Fitzpatrick T, Wan B, Day S, Mathews A, Tucker JD. Community advisory boards and research ethics in low-income and middle-income countries: a scoping review. Lancet. (abstract). 2018;392(Supple 1):42. https:// doi.org/10.1016/S0140-6736(18)32671-0.

\section{Publisher's Note}

Springer Nature remains neutral with regard to jurisdictional claims in published maps and institutional affiliations.
Ready to submit your research? Choose BMC and benefit from:

- fast, convenient online submission

- thorough peer review by experienced researchers in your field

- rapid publication on acceptance

- support for research data, including large and complex data types

- gold Open Access which fosters wider collaboration and increased citations

- maximum visibility for your research: over $100 \mathrm{M}$ website views per year

At $\mathrm{BMC}$, research is always in progress.

Learn more biomedcentral.com/submission 